\title{
Paecilomyces fumosoroseus blastospore production using liquid culture in a bioreactor
}

\author{
Mónica Guadalupe Lozano-Contreras*, Myriam Elías-Santos, Catalina Rivas-Morales, Hugo \\ Alberto Luna-Olvera, Luis Jesús Galán-Wong and María Guadalupe Maldonado-Blanco
}

Instituto de Biotecnología, Facultad de Ciencias Biológicas. Universidad Autónoma De Nuevo León (UANL), Av. Pedro de Alba y Manuel L. Barragán, Ciudad Universitaria, CP. 66450, A.P. 414 y 2790 San Nicolás de los Garza, Nuevo León, México.

Accepted 7 August, 2007

\begin{abstract}
There are many advantages to using liquid cultures for the production of blastospores. These include mainly the processes of scale up which are relatively easy, as well as the control of parameters such as temperature, aeration and $\mathrm{pH}$. In this work, we evaluated the production of Paecilomyces fumosoroseus blastospores using a low-cost liquid culture medium in a fermenter in comparison to a medium commonly used for this purpose, with regard to yield and viability of blastospores. The two media contained the same concentration of glucose but differed in N source (M1 containing casamino acids and M2 provided with collagen peptone and yeast extract). Starting with an inoculum of $1 \times 10^{6}$ blastospores $/ \mathrm{ml}$, M2 medium produced $2 \times 10^{10}$ blastospores $/ \mathrm{ml}$ after incubation for $72 \mathrm{~h}$ at $520 \mathrm{rev} / \mathrm{min}$ agitation and $1 \mathrm{v} / \mathrm{v} / \mathrm{m}$ (volume air/volume liquid.min) aeration, while only $2.4 \times 10^{8} / \mathrm{ml}$ were produced with M1. In addition, the microorganisms in medium M1 grew more slowly during log phase and reached an earlier plateau at $36 \mathrm{~h}$ fermentation. The medium containing collagen peptone and yeast extract is an excellent alternative for the production of $\boldsymbol{P}$. fumosoroseus blastospores, providing lower cost, higher yield and shorter propagation time, but formulation does need to be improved.
\end{abstract}

Key words: Collagen peptone, low cost, short times of propagation, fed-batch.

\section{INTRODUCTION}

The importance of the production of Paecilomyces fumosoroseus blastospores resides in their toxic effectiveness as a control agent in combating pests that affect various agricultural crops. Liquid-culture production of blastospores is a suitable biotechnological process from the point of view of efficiency and profitability, when compared with the production of spores on solid-culture surfaces or using two-phase fermentation. The use of liquid medium has shown good results in the production of $P$. fumosoroseus (Jackson et al., 2004), since it produces different morphological forms (mycelia, conidia and blastospores) such as with the fungus described by López et al. (2000). In this case, blastospores are produced, which are desired for their virulence and shorter time necessary for infection to occur. Therefore, the bio-

\footnotetext{
${ }^{\star}$ Corresponding author. E-mail: qbpmonik@terra.com.mx. Tel/Fax: + 52-81-83-294110 ext 6437 .
}

reactor plays a fundamental role in the development of liquid culture, simplifying production (requiring a shorter time) and providing optimized conditions for nutrition. Furthermore, important parameters such as temperature, aeration, $\mathrm{pH}$ and ease of product recovery translate into simplified mass-production, lower production costs and less time required, in comparison to fermentation on solid substratum. With the aim of examining other options for the propagation of $P$. fumosoroseus and production of blastospores in liquid medium, the present study evaluated production using a liquid culture medium consisting of a low-cost source of nitrogen at the fermentation level.

\section{MATERIALS AND METHODS}

Preparation of the inoculum

P. fumosoroseus (strain 612) was kindly provided by Mycotech Corp., Butte, MT, USA. This strain was isolated in 1993 from a diseased adult silverleaf whitefly (Bemisia argentifolii) in Weslaco, 
TX, USA. Stock cultures were grown as single-spore isolates on potato dextrose agar (PDA) for 21 days at room temperature and stored as $1 \mathrm{~mm}$ PDA plugs in $10 \%$ glycerol at $-80^{\circ} \mathrm{C}$ until use. For liquid-culture studies, conidia were produced by inoculating Sabouraud dextrose agar (Difco Laboratories, Detroit, MI, USA) plates with glycerol stock cultures of $P$. fumosoroseus. These cultures were grown at room temperature $\left(26-28^{\circ} \mathrm{C}\right)$ until sporulation occurred (2 - 3 weeks).

\section{Culture media}

Two liquid culture media were used, with the same concentration of carbohydrates $(C)$ but different sources of nitrogen $(N)$. M1 refers to a culture medium containing casamino acids (Probiotek, San Nicolás de los Garza, N.L. México) as the nitrogen source added at $18 \mathrm{~g} / \mathrm{l}$ and glucose as the carbon source (M1) at $80 \mathrm{~g} / \mathrm{l}$, which has been patented and described by Jackson et al. (1997). M2 refers the other culture medium used, which was developed and patented by Rivas-Morales (1998), registration number 9810892, containing collagen peptone (15 g/l) (Sensient, Jalisco México), yeast extract (5 $\mathrm{g} / \mathrm{l})$ (Sensient, Jalisco México), and glucose (80 $\mathrm{g} / \mathrm{l})$ as the source of carbon (M2).

\section{Conditions for propagation in the bioreactor}

The production of $P$. fumosoroseus blastospores was performed in a 5 liter bioreactor (model MF-114 New Brunswick Scientific Co., NJ, USA) with a 14 liter nominal volume. Agitation was carried using two Rushton impeller pH adjustment at 5.5 was automatically controlled by the fermenter control unit, which was done by the addition of either $2 \mathrm{~N} \mathrm{H}_{3} \mathrm{PO}_{4}$ or $2 \mathrm{~N} \mathrm{NaOH}$, achieved by peristaltic pumps. The temperature was adjusted to $28^{\circ} \mathrm{C}$, the agitation rate was $520 \mathrm{rev} / \mathrm{min}$ (revolutions per minute), and the aeration rate was set at $1 \mathrm{v} / \mathrm{v} / \mathrm{m}$ (volume air/volume liquid.min) as described previously by Elías-Santos (2002). Foam formation was suppressed with sterile Antifoam Type "A" (Dow Corning Production, USA). The bioreactor was inoculated with $2 \mathrm{ml}$ seed inoculum containing $1 \times 10^{6}$ blastospores $/ \mathrm{ml}$ as previously described by Jackson et al. (1997). During fermentation, dry weight, reducing sugar consumption and blastospore concentration were monitored every $12 \mathrm{~h}$, taking $5 \mathrm{ml}$ samples.

\section{Growth measurements}

Blastospore concentrations were measured microscopically using a hemacytometer after appropriate dilution $\left(10^{6}-10^{9}\right.$ times dilutions). For dry weight determinations, a sample of $1.0 \mathrm{ml}$ of culture was vacuum-filtered on a pre-dried, weighed $2.5 \mathrm{~cm}$ filter (GF/A; Whatman Inc, Clifton, NJ, USA) and washed with $1 \mathrm{ml}$ deionized water. Filters were dried at $100^{\circ} \mathrm{C}$ for $12 \mathrm{~h}$ and weighed. Each dry weight determination was performed in triplicate. Glucose concentration in the medium was determined using the DNS method (3, 5dinitrosalicylic acid) described by Greenman et al. (1981).

\section{Determination of the volumetric mass transfer coefficient $\left(k_{L} a\right)$}

The $k_{L}$ a was determined by the dynamic method (Humphrey, 1967) which uses the formula NA $=k_{L} a\left(C^{*}-C_{L}\right)=$ OUR, where NA $=$ volume-dependent mass transfer $\left(\mathrm{gO}_{2} / \mathrm{l} / \mathrm{h}\right), \mathrm{KL}=$ transfer coefficient at the phase boundary, $a=$ specific exchange surface, $k_{L} a=$ volumetric oxygen transfer coefficient $\left(\mathrm{h}^{-1}\right), \mathrm{C}^{*}=$ saturation value of the dissolved gas at the phase boundary (equivalent to $6.3 \mathrm{mgO}_{2} / \mathrm{l}$ in Mty, México at $0.999 \mathrm{~atm}), \mathrm{CL}=$ concentration of the dissolved gas $(\mathrm{g} / \mathrm{l})$ (at a given time), and OUR = oxygen uptake rate $\left(\mathrm{gO}_{2} / \mathrm{l} / \mathrm{h}\right)$.
Based on the formula above, the oxygen uptake rate $N A /\left(C^{*}-C_{L}\right)$ becomes NA = OUR. The oxygen uptake rate by the microorganism (NA) was determined based on the slope obtained by plotting the decline in dissolved oxygen concentration against elapsed time (in s) in the culture growing in log phase with the air flow and agitation shut off. Oxygen readings could thereby be obtained using a dissolved oxygen electrode during the fermentation runs.

\section{Recovery and formulation of the blastospores}

After $72 \mathrm{~h}$ incubation time, the culture was recovered, and the blastospores were harvested by filtering twice with a double layer of cheesecloth to eliminate the residual mycelium. Afterward, the culture was separated into two parts: the first part was formulated with $5 \%(\mathrm{w} / \mathrm{v})$ diatomaceous earth $\left(\mathrm{HYFLO}^{\circledR}{ }^{\circledR}\right.$, Celite Corp., Lompoc, CA, USA) and then filtered by vacuum-filtration on a Buchner funnel using Whatman No.1 filter paper. The support (diatomaceous earth) was thoroughly mixed with the filtered blastospore concentrates and excess liquid was removed from the mixture The resulting $P$. fumosoroseus blastospore formulations were allowed to air-dry over-night at room temperature $\left(26-28^{\circ} \mathrm{C}\right)$, and finally these were heat-sealed in plastic bags and stored at $4^{\circ} \mathrm{C}$. The second part containing blastospores only was stored in a dark bottle without any support at $4^{\circ} \mathrm{C}$ temperature.

\section{Blastospore viability test}

The survival of the two batches, blastospores that were formulated and air-dried and those without support was assessed weekly. At least three heat-sealed samples of each batch of $P$. fumosoroseus were opened and $0.2 \mathrm{~g}$ of the dried spore preparation and $1 \mathrm{ml}$ of the blastospore culture without support were obtained and placed in a $250 \mathrm{ml}$ baffled shaker flask containing $50 \mathrm{ml}$ of Sabouraud dextrose broth (Difco Laboratories, Detroit, MI, USA), and the flasks incubated on a rotatory shaker $\left(300 \mathrm{rev} / \mathrm{min}, 28^{\circ} \mathrm{C}\right)$. After incubation, three aliquots of each blastospore suspension were placed on a microscope slide and germination was assessed by counting a group of 100 blastospores per aliquot. Blastospores with the formation of a germ tube at least as long as the length of the spore were scored as viable. Desiccation tolerance (or spore survival) data were analyzed using Student's t-test, where differences in mean values were considered significant at $p \leq 0.05$.

\section{RESULTS}

\section{Yield}

The production of blastospores of $P$. fumosoroseus 612 in a bioreactor after $12 \mathrm{~h}$ fermentation did not differ significantly between the two media studied. However, blastospore yield did differ after $24 \mathrm{~h}$ fermentation, where medium M2 produced $5.1 \times 10^{7}$ blastospores $/ \mathrm{ml}$ while medium M1 had $1.5 \times 10^{6}$ blastospores $/ \mathrm{ml}$. The greater number of blastospores produced in medium M2 compared to medium M1 at $24 \mathrm{~h}$ was highly significant as determined by Student's t-test at $p \leq 0.01$ (Figure 1).

\section{Growth kinetics based on dry weight}

With regard to the initial dry weight obtained with the two media, no difference was observed at $12 \mathrm{~h}$ fermentation. Afterward, at the subsequent sampling times $(24,36,42$, 60 and $72 \mathrm{~h}$ ), significantly greater dry weights were ob- 


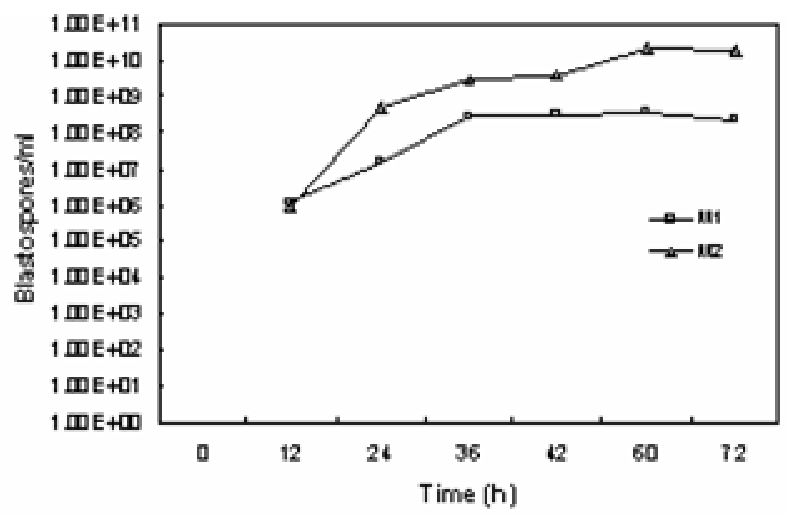

Figure 1. Growth of $P$. fumosoroseus in a bioreactor $\left(28^{\circ} \mathrm{C}, 520 \mathrm{rev} / \mathrm{min}, 1 \mathrm{v} / \mathrm{v} / \mathrm{m}\right)$ in liquid media M1 (casamino acids) and M2 (collagen peptone and yeast extract).

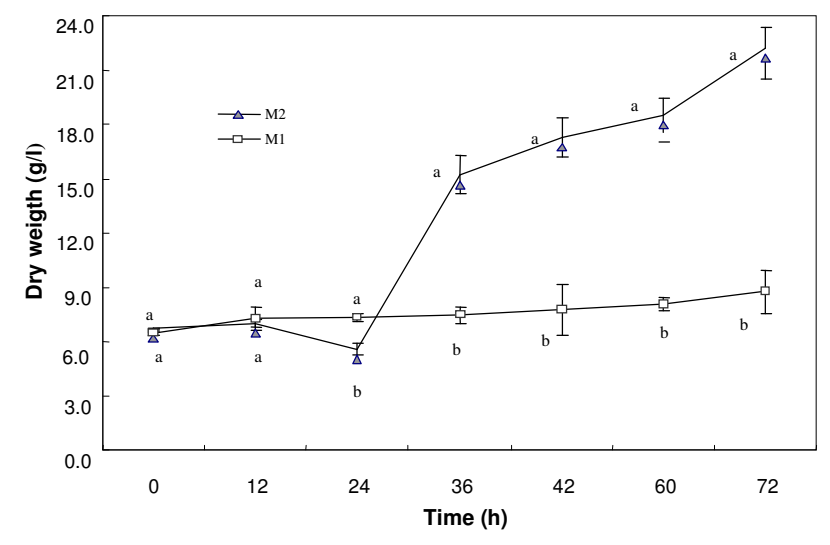

Figure 2. $P$. fumosoroseus dry weight obtained in a bioreactor $\left(28^{\circ} \mathrm{C}, 520 \mathrm{rev} / \mathrm{min}, 1 \mathrm{v} / \mathrm{v} / \mathrm{m}\right.$ ) in liquid media M1 (casamino acids) and M2 (collagen peptone and yeast extract). Different letters at each time indicate significant differences at $p \leq 0.05$.

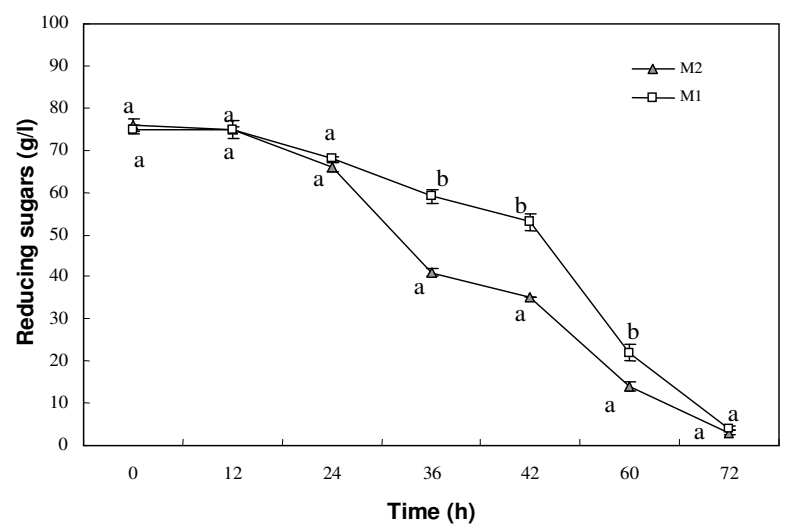

Figure 3. Consumption of reducing sugars by $P$. fumosoroseus in a bioreactor $\left(28^{\circ} \mathrm{C}, 520 \mathrm{rev} / \mathrm{min}, 1 \mathrm{v} / \mathrm{v} / \mathrm{m}\right)$ in liquid media M1 (casamino acids) and M2 (collagen peptone and yeast extract). Different letters at each time indicate significant differences at $p \leq 0.05$.

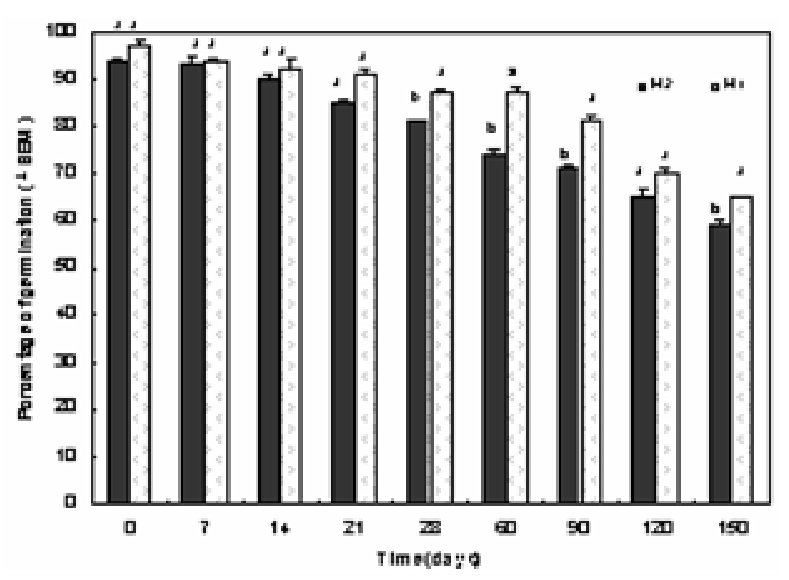

Figure 4. Survival of $P$. fumosoroseus blastospores produced in two media differing in nitrogen source (media M1 and M2) after formulation with $5 \%(\mathrm{w} / \mathrm{v})$ diatomaceous earth and storage at $4^{\circ} \mathrm{C}$. Different letters at each time indicate significant differences at $p \leq 0.05$.

served for both media, as determined by Student's t-test at $p \leq 0.05$. The final dry weight obtained with medium M2 was $15.5 \mathrm{~g} / \mathrm{l}$, whereas that obtained with medium M1 was $9.3 \mathrm{~g} / \mathrm{l}$ (an increase of 66\%) (Figure 2).

\section{Growth kinetics based on sugar consumption}

The initial consumption of sugar was similar in the two media for up to $36 \mathrm{~h}$ fermentation, after which sugar was consumed more quickly in medium M2. Reducing sugar concentration was $41 \mathrm{~g} / \mathrm{l}$ at $36 \mathrm{~h}$ (for a consumption of 39 $\mathrm{g} / \mathrm{l})$. The subsequent sampling times $(36,42$ and $60 \mathrm{~h})$ also showed differences in consumption, but at the end of fermentation the two media were similar with regard to sugar consumption (Figure 3 ).

\section{Volumetric mass transfer coefficient $\left(k_{L} a\right)$}

The $k_{L} a$ value obtained was $115.38 \mathrm{~h}^{-1}$ for media M1 and M2. This value, according to Quintero (1981) is inside an acceptable range because values for mechanical agitation tanks are between 60 and $240 \mathrm{~h}^{-1}$.

\section{Blastospore viability test}

The survival of the air-dried, formulated blastospores is shown in Figure 4 and corresponds to the average value for 3 experiments. The initial viability of the air-dried, formulated blastospore preparations (with diatomaceous earth) produced with M1 was > 97 and $94 \%$ for M2. For the subsequent sampling days $(7,14$, and 21$)$, the blastospores produced in both media showed the same viability percentages without significant differences. However, for 


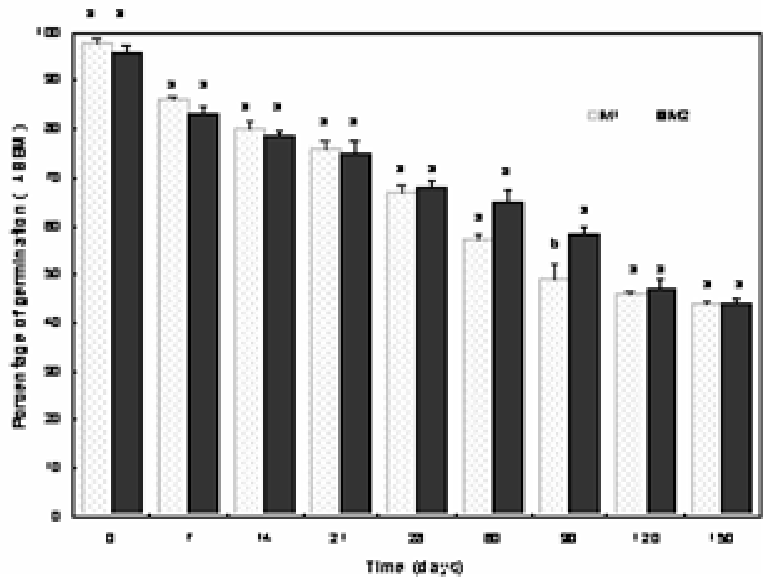

Figure 5. Survival of $P$. fumosoroseus blastospores produced in two media differing in nitrogen source (media $\mathrm{M} 1$ and M2) without support and after storage at $4^{\circ} \mathrm{C}$. Different letters at each time indicate significant differences at $p \leq 0.05$.

the next storage days $(28,60$ and 90$)$, the blastospores produced in medium M1 showed higher viability percentages than blastospores obtained in medium M2, but at 120 days storage, the viability percentages were similar. Finally, at 150 days storage, the viability percentage of blastospores produced in medium M1 was significantly higher than that of blastospores obtained in medium M2. For blastospore viability without support, the results are shown in Figure 5. Blastospore survival for the two media was very similar, declining with sampling day until 60 days storage. However, for 90 days, blastospore viability for medium M2 was significantly higher than blastospore viability for medium $\mathrm{M} 1$, and finally at 150 days storage, both viabilities were similar ( $46 \%$ less than initial viability).

\section{DISCUSSION}

In this study, the production of $P$. fumosoroseus blastospores in a bioreactor was increased by using a culture medium of simple composition and conditions of $520 \mathrm{rev} / \mathrm{min}$ and $1 \mathrm{v} / \mathrm{v} / \mathrm{m}$ which had been found to be ideal in an earlier investigation by Elías-Santos (2002). The medium used for propagation produced $2 \times 10^{10}$ blastospores $/ \mathrm{ml}$, which we considered high, since it was much higher than that obtained by Vidal et al. (1998) who reported a low concentration of $3.2 \times 10^{8}$ propagules $/ \mathrm{ml}$ obtained in a medium containing glucose and yeast extract (Paris medium). Similarly, López et al. (2000), showed a production of $5 \times 10^{8}$ conidia/ml of $P$. fumosoroseus obtained in a fermenter with a medium containing glucose $(30 \mathrm{~g} / \mathrm{l})$ and $\mathrm{NH}_{4} \mathrm{NO}_{3}(0.7 \mathrm{~g} / \mathrm{l})$, with yeast extract added as the nitrogen source and cultured at operating conditions of $400 \mathrm{rev} / \mathrm{min}$ and $1.5 \mathrm{v} / \mathrm{v} / \mathrm{m}$. These references corroborate the fact that some ingredients, such as peptone and yeast extract, could help improve blastospore production. Additionally, if the operating conditions are improved for propagation in a bioreactor, using conditions like those in this study, blastospore production can reach more than $2 \times 10^{9}$ blastospores $/ \mathrm{ml}$, as achieved with medium M2. Regarding biomass level, $15.5 \mathrm{~g} / \mathrm{l}$ was obtained in medium M2 after $72 \mathrm{~h}$, compared to $9.3 \mathrm{~g} / \mathrm{l}$ in medium M1. In this respect, Cliquet and Jackson (1999) reported that maximum dry weight is associated with maximum blastospore production, as shown in this work with medium M2. For sugar consumption, both culture media reached their growth potential at $72 \mathrm{~h}$ fermentation with final medium glucose levels of 3 and $4 \mathrm{~g} / \mathrm{l}$ for $\mathrm{M} 2$ and $\mathrm{M} 1$, respectively. The volumetric mass transfer coefficient $\left(k_{L} a\right)$ value obtained was $115.38 \mathrm{~h}^{-1}$ for media M1 and M2. This value, according to Quintero (1981), is inside an acceptable range since the values for mechanical agitation tanks are between 60 and $240 \mathrm{~h}^{-1}$.

The blastospores obtained in both media, were stored at $4^{\circ} \mathrm{C}$, as had been done in previous studies, such as the one reported by Jackson (1999), which showed that temperature and humidity affect the germination and survival of the fungus. Jackson et al. (1997) concluded that blastospores maintained at $22^{\circ} \mathrm{C}$ lost their viability after 30 days. Under the conditions used in this study, during the first 14 days storage, the viability of the blastospores produced in both culture media, showed the same survival rate, without significant differences, $(t=1.7500$, d.f $=2)$, whereas for the subsequent days, $(21-90)$, viability shown by the blastospores produced in medium M1 was higher than that of the blastospores produced in medium M2. These results were similar to those obtained by Sandoval-Coronado et al. (2001), but the differences were not substantial, given that percent viability differed only $4-15 \%$. For the final sampling (150 days storage), the blastospores obtained in the two media and formulated with diatomaceous earth and maintained at $4^{\circ} \mathrm{C}$, showed between $59-65 \%$ viability. These values were higher than those reported by Sandoval-Coronado et al. (2001) of only $10-20 \%$ viability after 63 days storage. In other words, his results showed that viability was lost at a much earlier stage compared to the findings of the present study. The viability of the blastospores stored without any support, as expected, showed a continuous decline, until it reached less than $46 \%$ viability after five months storage at $4^{\circ} \mathrm{C}$. Thus, the temperature used for the storage of blastospores is a critical factor in their survival, together with the production medium and the support used during drying, which can have an impact on desiccation tolerance and storage stability of $P$. fumosoroseus blastospores. The formulations or supports must provide a matrix that allows the blastospores to acclimate to a desiccated state, as well as protect them from deleterious conditions during storage. Although good results have been obtained with calcined clays (SandovalCoronado et al., 2001), new formulations need to be opti- 
mized to improve the desiccation tolerance and storage stability of blastospores of $P$. fumosoroseus.

\section{REFERENCES}

Cliquet S, Jackson MA (1999). Influence of conditions on production and freeze-drying tolerance of Paecilomyces fumosoroseus blastospores. J. Ind. Microbiol. Biotechnol. 23: 97-102.

Elías-Santos M (2002). Efecto de las condiciones operacionales de fermentación sobre la producción de Paecilomyces fumosoroseus cepa 612 en cultivo sumergido. PhD dissertation, Universidad Autónoma de Nuevo León, Nuevo León, México. pp. 56-70.

Greenman J, Holland KT, Cunliffe WJ (1981). Effects of Glucose concentration on Biomass, Maximum Specific Growth Rate and Extracellular Enzyme Production by Three Species of Cutaneous Propionibacterium Grow in Continuous Culture. J. Gen. Microbiol. 127: 371-376.

Humphrey AM (1967). A critical review of hydrocarbon fermentations and their industrial utilization. Biotechnol. Bioeng. 9: 3-24.

Jackson MA, McGuire M, Lacey L, Wraight S (1997). Liquid culture production of dessication tolerant blastospores of the bioinsecticidal fungus Paecilomyces fumosoroseus. Mycol. Res. 101: 35-41.

Jackson MA (1999). Method for producing desiccation tolerant Paecilomyces fumosoroseus spores. U.S. Patent \# 5,968,808. Oct.19. 1999.

Jackson MA. Payne AR, Odelson DA (2004). Liquid-culture production of blastospores of the bioinsecticidal fungus Paecilomyces fumosoroseus using portable fermentation equipment. J. Ind. Microbiol. Biotechnol. 31: 149-154.

López-López EV, Chavarria-Hernández N, Fernández-Sumano P, De la Torre M (2000). Fermentation processes for bioinsecticide production. An overview. Recent Res. Dev. Biotechnol. Bioeng. 3: 120.
Quintero RR (1981). Ingeniería bioquímica (Teorías y aplicaciones). Editorial Alambra Mexicana, S.A. México, pp. 45-107.

Rivas-Morales C (1998). Diseño de un medio de cultivo para la producción de biomasa de Nocardia brasiliensis HUJEG-1 a escala piloto para la obtención de proteasas caseinoliticas. PhD dissertation, Universidad Autónoma de Nuevo León, Nuevo León, México. pp. 4580.

Sandoval-Coronado CF, Luna-Olvera HA, Arévalo-Niño K, Jackson MA, Poprawski TJ, Galán-Wong L (2001). Drying and formulation of blastospores of Paecilomyces fumosoroseus (Hyphomycetes) produced in two different liquid media. World J. Microbiol. Biotechnol. 17: 423-428.

Vidal C, Fargues J, Lacey LA, Jackson MA (1998). Effect of various liquid culture media on morphology, growth, propagule production, and pathogenic activity to Bemisia argentifolii of the entomopathogenic Hyphomycetes, Paecilomyces fumosoroseus. Mycopathology 143: 33-46. 